\title{
Effect of Substituting Purple Rice Flour for Wheat Flour on Physicochemical Characteristics, In Vitro Digestibility, and Sensory Evaluation of Biscuits
}

\author{
Warinporn Klunklin (i) and Geoffrey Savage \\ Department of Wine, Food and Molecular Biosciences, Faculty of Agriculture and Life Sciences, Lincoln University, Lincoln 7647, \\ Christchurch, New Zealand
}

Correspondence should be addressed to Warinporn Klunklin; warinporn.klunklin@lincolnuni.ac.nz

Received 6 March 2018; Revised 24 April 2018; Accepted 26 April 2018; Published 15 May 2018

Academic Editor: Encarna Aguayo

Copyright (c) 2018 Warinporn Klunklin and Geoffrey Savage. This is an open access article distributed under the Creative Commons Attribution License, which permits unrestricted use, distribution, and reproduction in any medium, provided the original work is properly cited.

Purple rice flour contains high levels of a number of antioxidant compounds; however, it has seldom been used as an ingredient in bakery products. The aim was to increase the nutritional value of biscuits by adding purple rice flour to a basic wheat flour biscuit. The substitution of purple rice flour in place of wheat flour modified the characteristics of the biscuits in terms of increasing the nutritional values. They contained high fiber, antioxidants, and antioxidant activities, while slightly changing the physical properties such as hardness and spread ratio. The study showed that the protein digestibility increased as the content of the purple rice flour was increased in the biscuit mix. The 100\% purple rice flour biscuits had the lowest predicted glycemic index (pGI) of all the biscuits. Sensory analysis showed that the overall acceptability of the blended flour biscuits at 25 and $50 \%$ substitution levels was slightly less than that of the control biscuits with only $9 \%$; however, the scores were above 5 which means the panelists still liked the biscuits a lot. Overall, the inclusion of purple rice flour in biscuits mix increased crude protein content, protein digestibility, and bioactive compounds with acceptable sensory scores from consumers up to $50 \%$ substitution of purple rice.

\section{Introduction}

Purple rice (Oryza sativa L. var. Sanpatong) is a popular cultivar grown widely in Northern Thailand. It has become well known because of its interesting color, good taste, and lower commodity price compared to wheat flour [1]. Purple rice has also become popular because it contains high amounts of bioactive compounds such as phenolic acids and anthocyanins. It also contains higher levels of dietary fiber than wheat flour [2]. Cyanidin-3-O-glucoside and peonidin3-O-glucoside are present in the pericarp and aleurone layers, and high levels of phenolic acids are found in the outer layers of the grain [1]. All of these bioactive compounds give the grain high antioxidant activities [1]. Red rice, black rice, and purple wheat are all valued for their natural antioxidant content [2, 3]. Antioxidants play important roles in lowering low-density lipoprotein cholesterol
(LDL), improving lipid profiles, and reducing inflammation due to free radical inhibition [4]. In addition, purple rice contains high amounts of dietary fiber [1].

Biscuits made from wheat flour are one of the most widely eaten consumer products around the world. They are an affordable product, and they have a good taste and a long shelf life [5]. Unfortunately, biscuits usually contain high levels of easily digested starch, sugar, and butter, and low levels of dietary fiber which nutritionists suggest make them a rather unhealthy constituent of our diet. Bakers are well aware of these issues, and they have shown some interest in developing biscuits, which can be regarded as functional foods containing less butter $[3,6,7]$. So far, bakery research has attempted to make more healthy products by incorporating new ingredients into biscuit mixes in order to increase their nutritional and textural qualities [5]. The texture, flavor, and appearance of the biscuits are major 
TABLE 1: Formulation of biscuits supplemented with purple rice flour.

\begin{tabular}{|c|c|c|c|c|c|}
\hline \multirow[t]{2}{*}{ Ingredients (g) } & \multirow[t]{2}{*}{ Control } & \multicolumn{4}{|c|}{$\begin{array}{l}\text { Purple rice flour substitution } \\
\qquad(\%)\end{array}$} \\
\hline & & 25 & 50 & 75 & 100 \\
\hline Refined wheat flour & 100 & 75 & 50 & 25 & - \\
\hline Purple 1 & - & 25 & 50 & 75 & 100 \\
\hline Butter & 75 & 75 & 75 & 75 & 75 \\
\hline Sugar & 62.5 & 62.5 & 62.5 & 62.5 & 62.5 \\
\hline Egg & 112.5 & 112.5 & 112.5 & 112.5 & 112.5 \\
\hline Salt & 0.75 & 0.75 & 0.75 & 0.75 & 0.75 \\
\hline Sodium bicarbonate & 4.5 & 4.5 & 4.5 & 4.5 & 4.5 \\
\hline Xanthan gum & 1.25 & 1.25 & 1.25 & 1.25 & 1.25 \\
\hline
\end{tabular}

attributes that affect biscuit acceptability [8]. Unfortunately, rice protein cannot generate a viscoelastic network like gluten in wheat, which retains carbon dioxide during biscuit dough fermentation. So the addition of rice to a biscuit mix can have a significant effect on the textural qualities of the cooked biscuit. However, biscuits require a lower specific volume compared to the familiar structure of bread [6]. In attempts to reduce cost, many studies have investigated the properties of biscuits using different types of rice flours such as white rice flour [8], waxy rice flour [9], brown rice flour [10], and a composite rice flour together with green gram flour and potato flour [11]. Recently, products with high protein and fiber contents are more commonly chosen by consumers in order to combat diseases such as diabetes and obesity. Therefore, dietary fiber in bran and the germ of cereal grains has been added to biscuit formulations, which originally contained almost no dietary fiber in the original recipe [8]. Substitution of purple rice flour for wheat flour will definitely reduce the wheat gluten content, but purple rice flour has potential as an inexpensive raw material for biscuits as it has good textural qualities with high contents of bioactive compounds and dietary fiber. However, the development of new healthy products has to have acceptable sensory attributes, as the product will become a marketing failure. Therefore, the objective of this study was to evaluate the physicochemical characteristics and antioxidant properties of raw flours and biscuits substituted with different levels of purple rice flour. Finally, the preferences for the biscuits made from different levels of purple rice flour were evaluated using consumer taste tests.

\section{Materials and Methods}

2.1. Raw Materials. The biscuits were prepared by the substitution of purple rice flour for refined wheat flour (Pams Products Ltd., Auckland, NZ), purple rice (Oryza sativa L. var. Sanpatong) (Big T. supermarket, Riccarton, Christchurch, NZ) purchased in $5 \mathrm{~kg}$ bags, baking powder (Edmonds Limited, Goodman Fielder Ltd., Auckland, NZ), xanthan gum (Lotus Foods Pty Ltd., Cheltenham, Victoria, Australia), butter (Dairyworks Ltd., Hornby, Christchurch, NZ), castor sugar (Pams Products Ltd., Auckland, NZ), salt (Pams Products Ltd., Auckland, NZ), whole egg (Pams Products Ltd., Auckland, NZ), and vanilla extract (Pams
Products Ltd., Auckland, NZ). All ingredients were of food grade. The experimental biscuits were made by substituting purple rice flour for wheat flour at levels of $25,50,75$, and $100 \%(\mathrm{w} / \mathrm{w})$ of the total flour weight. The control biscuits were made from refined wheat flour.

2.2. Biscuit Preparation. The control biscuits were prepared from blended wheat flour, and the whole purple rice grains were milled using a Whisper Mill (Grote Molen Inc., USA) as purple rice flour was not available in New Zealand. All ingredients are shown in Table 1. The dough was rolled out to a thickness of $4 \mathrm{~mm}$ using an adjustable rolling pin (Joseph Joseph 20085, Joseph Joseph Ltd., London, UK) and was then cut out with a $5 \mathrm{~cm}$ diameter biscuit cutter. The dough was then baked in the oven (Bakbar Turbofan 32 Max, Ali Group company, Milan, Italy) at $170^{\circ} \mathrm{C}$ for $9 \mathrm{~min}$ and cooled on a wire grid at room temperature for $15 \mathrm{~min}$. Physical analysis and sensory evaluations were carried out on the freshly baked biscuits, whereas chemical analysis such as antioxidants and in vitro digestibility was carried out on the ground samples.

2.3. Proximate Analysis. Moisture content of the biscuits was measured by gravimetric method using the oven at $105^{\circ} \mathrm{C}$ for $18 \mathrm{~h} \mathrm{[12]}$. Total nitrogen was determined using the Dumas method; the factor 6.25 was used to calculate the crude protein content of the biscuits [12]. Fat and ash contents of the biscuits were also determined according to the methods of the Association of Official Analytical Chemists [12]. The carbohydrate was calculated by the difference according to the AOAC method [12]. Total starch content was determined using the full instruction and reagents from Megazyme starch assay kit (Megazyme International Ireland Ltd., Wicklow, Ireland) (Approved Method 76-13) [13]. Total dietary fiber content of biscuits was evaluated using the total dietary fiber assay kit (Sigma-Aldrich, MO, USA). All proximate compositions were analyzed in triplicate.

\subsection{In Vitro Digestibility}

2.4.1. Protein Digestibility. The in vitro protein digestibility was carried out by multienzyme solution according to Akeson and Stahmann [14] method. The two stages of in vitro digestion of pepsin from porcine gastric mucosa (Sigma-Aldrich, USA, 66 units/mg protein) followed by pancreatin from porcine pancreas (AppliChem Chemica Synthesis, Germany, $30.315 \mathrm{units} / \mathrm{mg}$ protein) were used to stimulate the gastric and intestinal digestion in humans. The simulated protein solution of each sample was centrifuged at $1600 \times \mathrm{g}$ for $10 \mathrm{~min}$. The supernatants were determined for nitrogen contents using an Elementar (Hanau, Germany) Vario TOC cube instrument fitted with a chemiluminescence detector for determining total bound nitrogen (TNb). The analysis was carried out in triplicate.

2.4.2. Starch In Vitro Digestion. The in vitro digestion of biscuits was determined using a simulated gastric digestion 
followed by pancreatin enzymes (AppliChem Chemica Synthesis, Germany, 30.315 units/mg protein) [15]. The hydrolyzed glucose contents were measured using the glucose released method at following times: $0,20,60,90,120$, and $180 \mathrm{~min}$. The glucose released was measured using a glucose oxidase-peroxidase kit (K-GLOX, Megazyme Bray, Co., Wicklow, Ireland). The digested starch fractions were centrifuged at $180 \times \mathrm{g}$ for $5 \mathrm{~min}$, and then, the supernatants were read at $530 \mathrm{~nm}$ (V-1200 spectrophotometer, Global Science, Auckland, New Zealand).

2.5. Predicted Glycemic Index ( $p G I)$. The hydrolysis index (HI) was derived from the area under the curve of glucose released from each sample $(0-180 \mathrm{~min})$ divided by the area under the curve from a reference food ( $50 \mathrm{~g}$ white bread). The predicted glycemic index (pGI) was calculated using the equation of Goni et al. [16]: Predicted glycemic index $=8.198+0.549 \times \mathrm{HI}$.

2.6. Physical and Texture Characteristics. The hardness $(N)$ of freshly baked biscuits was measured using a texture analyzer (TA-XT2i, Stable Micro System, Godalming, UK) equipped with $30 \mathrm{~kg}$ load cell. A small three-point bending test rig with sharp-blade cutting probe was used [5]. The first peak of each penetration was recorded as the hardness force.

Fifteen minutes after baking, six freshly baked biscuits were weighted, and the width $(W)$, thickness $(T)$, and biscuit spread ratio $(W / T)$ were determined (AACC method 10-50.05) [17].

2.7. Color Determination. Surface CIE color values $\left(L^{*} a^{*} b^{*}\right)$ were taken at the center of each biscuit using a Minolta Chroma Meter CR-410 (Konica Minolta, Chiyoda, Tokyo, Japan) [18]. The browning index was calculated using the following equation:

$$
\text { Browning index }=\frac{100(x-0.31)}{0.17},
$$

where $x$ is $\left(a^{*}+1.75 L^{*}\right) /\left(5.645 L^{*}+a^{*}-0.3012 b^{*}\right)$ [19]. Six replicates were performed for each sample in physical analysis.

\subsection{Extraction and Determination of Antioxidant Compounds} and Antioxidant Activities. All solutions were extracted according to Jang and $\mathrm{Xu}$ [1] and kept at $-20^{\circ} \mathrm{C}$ until further analysis. Samples $(1 \mathrm{~g})$ were added to $10 \mathrm{~mL}$ methanol acidified with $1.2 \mathrm{M} \mathrm{HCl}(50: 50, \mathrm{v} / \mathrm{v})$ before vortexing for $30 \mathrm{~s}$. Then, they were incubated in a water bath at $60^{\circ} \mathrm{C}$ for $1.5 \mathrm{~h}$. The extracts were centrifuged at $4500 \times \mathrm{g}$ for $10 \mathrm{~min}$. The total phenolic concentration of both the free and bound fractions was analyzed using the Folin-Ciocalteu assay as described in Kaneda et al. [20]. Total anthocyanin concentration was determined using the method previously described by Hosseinian et al. [4]. Total flavonoid concentration in both the free and bound fractions was determined using the protocol described by Ruangchakpet and Sajjaanantakul [19]. The determinations were carried out in triplicate.
For ABTS [2,2'-azinobis-(3-ethylbenzothiazoline-6sulfonic acid)], radical scavenging activity of the free and bound fractions was determined according to Re et al. [21]. The DPPH radical scavenging capacity (DPPH, 2,2-diphenyl2-picrylhydrazyl) was determined according to the method of Mahakunakorn et al. [22]. All determinations were carried out in triplicate.

2.9. Consumer Acceptance Test. Ninety panelists participated in this study. The panelists (19-60 years old) were students and staff members from the University campus. The study was approved by the Lincoln University Human Ethics Committee (number 2017-24). The panelists were asked to sign a standard consent form before evaluating the samples. The participants quantified their preferences using a sevenpoint hedonic scale $(1=$ dislike very much, $4=$ neither like nor dislike, $7=$ like very much) [11]. The samples were served one day after baking. The evaluations were carried out under standard conditions.

2.10. Statistical Analysis. Experimental data in this work were statistically analyzed by one-way ANOVA using a complete randomized design for all physicochemical experiments and a randomized complete block design for the sensory evaluation data. The mean values were analyzed by Duncan's multiple range test for a multicomparison of means. The level of significance was assigned at $p<0.05$. All statistical analyses were performed using the SPSS Statistics (v. 22.0, SPSS Inc., Chicago, IL, USA).

\section{Results and Discussion}

3.1. Basic Characteristics of Biscuits. The nutritional compositions of biscuits are shown in Table 2. The moisture content of biscuits increased linearly from 3.57 to $7.36 \%$ $(p<0.05)$ with the increased concentration of purple rice flour in the biscuit mix. Therefore, biscuits prepared from $100 \%$ purple rice flour had the highest moisture content due to the high fiber content and swelling power of purple rice flour. Water content in food products affects the texture and consumers' acceptability of the final quality of the biscuits [6]. The level of moisture was within the range of $10 \%$ moisture contents for baked products (cake, biscuits, and bread) to prevent spoilage and extend shelf life [23].

Crude protein contents significantly ranged from 5.82 (100\% purple rice biscuits) to $7.35 \%$ (the control biscuits). Torbica et al. [8] also observed a decrease in the protein contents with corresponding increase in the proportion of rice flour substituted for wheat flour in the biscuits. Protein and fat contents differed due to the rice cultivars and biscuit formulations $[8,24]$. Starch and protein contents are the major compositions in food products, affecting physicochemical characteristics, and play an important role in the final quality of the biscuits [6]. As far as only few studies focus on the in vitro protein digestibility of purple rice, no literature is also available on the in vitro digestibility of purple rice flour biscuits. However, this study found that the protein digestibility of the biscuits showed a significantly 
TABLE 2: Basic characteristics of the biscuits containing different levels of purple rice flours*.

\begin{tabular}{|c|c|c|c|c|c|}
\hline \multirow{2}{*}{ Nutritional properties } & \multirow{2}{*}{ Control wheat biscuit } & \multicolumn{4}{|c|}{ Purple rice flour substitution (\%) } \\
\hline & & 25 & 50 & 75 & 100 \\
\hline Moisture content (\%) & $3.57 \pm 0.06^{\mathrm{e}}$ & $4.60 \pm 0.12^{\mathrm{d}}$ & $5.64 \pm 0.08^{c}$ & $6.33 \pm 0.14^{\mathrm{b}}$ & $7.36 \pm 0.13^{\mathrm{a}}$ \\
\hline Crude protein $(\%)$ & $7.35 \pm 0.04^{\mathrm{a}}$ & $6.62 \pm 0.03^{b}$ & $6.61 \pm 0.02^{\mathrm{b}}$ & $6.13 \pm 0.04^{c}$ & $5.82 \pm 0.01^{\mathrm{d}}$ \\
\hline Protein digestibility (\%) & $41.13 \pm 0.53^{\mathrm{e}}$ & $60.15 \pm 0.29^{d}$ & $65.36 \pm 0.26^{\mathrm{c}}$ & $74.05 \pm 0.04^{\mathrm{b}}$ & $79.65 \pm 1.01^{\mathrm{a}}$ \\
\hline Total dietary fiber (\%) & $2.01 \pm 0.09^{\mathrm{d}}$ & $3.06 \pm 0.10^{c}$ & $3.26 \pm 0.04^{c}$ & $4.40 \pm 0.05^{\mathrm{b}}$ & $5.53 \pm 0.02^{\mathrm{a}}$ \\
\hline Total fat $(\%)$ & $28.43 \pm 0.14^{\mathrm{NS}}$ & $28.59 \pm 0.07$ & $28.36 \pm 0.20$ & $28.69 \pm 0.62$ & $29.22 \pm 0.46$ \\
\hline Ash (\%) & $1.69 \pm 0.02^{\mathrm{d}}$ & $1.86 \pm 0.01^{\mathrm{c}}$ & $2.16 \pm 0.02^{\mathrm{b}}$ & $2.26 \pm 0.01^{\mathrm{a}}$ & $2.32 \pm 0.04^{\mathrm{a}}$ \\
\hline Total carbohydrate (\%) & $59.22 \pm 0.14^{\mathrm{a}}$ & $58.83 \pm 0.12^{\mathrm{ab}}$ & $57.86 \pm 0.29^{\mathrm{b}}$ & $56.11 \pm 0.54^{\mathrm{c}}$ & $54.38 \pm 0.47^{\mathrm{d}}$ \\
\hline Total starch (\%) & $33.91 \pm 0.15^{\mathrm{a}}$ & $32.35 \pm 0.11^{\mathrm{b}}$ & $31.62 \pm 0.34^{\mathrm{bc}}$ & $30.89 \pm 0.19^{c}$ & $30.36 \pm 0.83^{\mathrm{c}}$ \\
\hline $\mathrm{AUC}^{\dagger}$ of digested starch $\left(\mathrm{mg} \mathrm{min} \cdot \mathrm{dL}^{-1}\right)$ & $668.69 \pm 0.95^{\mathrm{a}}$ & $607.66 \pm 0.56^{\mathrm{b}}$ & $559.38 \pm 0.43^{c}$ & $487.23 \pm 1.32^{\mathrm{d}}$ & $423.25 \pm 1.43$ \\
\hline $\mathrm{pGI}^{\ddagger}$ & $72.78 \pm 0.05^{\mathrm{a}}$ & $69.76 \pm 0.03^{b}$ & $67.38 \pm 0.02^{c}$ & $63.81 \pm 0.07^{\mathrm{d}}$ & $60.64 \pm 0.07^{\mathrm{e}}$ \\
\hline
\end{tabular}

*Values represent mean \pm standard error; in each row, sample means not having the same letter attached to them are significantly different (Duncan's multiple range test, $p<0.05$ ); NS = not significant difference. ${ }^{\dagger}$ Area under the curve (AUC) of digested starch can predict glycemic response of each biscuit. ${ }^{*}$ Predicted glycemic index.

increased trend for biscuits made from wheat-purple rice flour blends compared to the control biscuit. The in vitro protein digestibility of the control biscuit was $41.13 \%$, while that of the wheat-purple rice flour blend biscuits ranged from 60.15 to $79.65 \%$ (Table 2). Although substituting purple rice flour in the biscuits mix showed a decrease of crude protein content by $26.29 \%$, the protein digestibility increased $53.64 \%$ when compared to the control biscuits. The suppression effect of protein digestibility of gluten proteins after baking is a consequence of protein denaturation, structure, conformation, and degree of hydrolysis [25]. The fiber contents of the biscuits depend on the flour composition. Purple rice flour substitutions significantly increased fiber $(p<0.05)$ compared to the control biscuit with no significant difference in fat contents. Yawadio et al. [2] also reported that dietary fibers in pigmented rice are much more overwhelming than those in white rice. Fat content is another principal ingredient of biscuits which has an influence on texture characteristics [7]. All biscuits in this study contained a high fat content (mean 28.7\%) from butter, which is a natural fat to use as it gives a good flavor after baking [7]. However, it is rich in saturated fatty acids. Currently, consumers' awareness of low-fat products is increasing. It is possible to replace, at least partly, butter with healthier lipids such as extra virgin olive oil [7].

The starch content of purple rice blend flour biscuits ranged from 30.89 (75\% purple rice flour substitution) to $32.35 \%$ (25\% purple rice flour substitution) which was found to be statistically significant $(p<0.05)$. The control biscuit was reported $33.91 \%$ which is higher than blend flour biscuits (Table 2). The effects of purple rice flour on the in vitro starch digestion in biscuits were investigated by measuring the released reducing sugar contents degraded from starch by a digestive enzyme hydrolysis for $180 \mathrm{~min}$. Area under the curves (AUCs) of glucose released from starch digestion were determined after each sample digestion because it easily explains the glycemic response of the tested foods compared to the standard amount of white bread [26]. The control biscuit had the highest AUC content, followed by substitution with $25 \%$ purple rice flour, $50 \%$ purple rice flour, $75 \%$ purple rice flour, and $100 \%$ purple rice flour, respectively, due to the fibers and proteins in purple rice acting as a barrier towards starch digestibility which can cause slower and lower increase of the glucose in the in vitro method [18]. The $100 \%$ purple rice biscuit showed the lowest starch digestions according to the low starch hydrolysis determined. A 57.99\% reduction was observed in starch digestibility when $100 \%$ purple rice flour was replaced with the wheat flour in the biscuit mixtures. Similar to the observation of An et al. [26], the low starch digestibility is influenced by the protein bodies that can restrict the starch granule swelling and starch gelatinization.

The pGI values of the biscuits were calculated based on the correlation equations between $\mathrm{HI}$ and estimated GI derived from the starch digestion of each biscuit. The pGI values of the biscuits were investigated depending on the level of purple rice flour substitutions (Table 2). The calculated pGI values of the biscuits decreased from 72.8 units down to 60.64 as the level of purple rice flour was increased in the biscuit mix (Table 2). The trend of pGI of wheat-black rice blend flours was similar to the study of An et al. [26]. The biscuit compositions have been changed due to the purple rice flour which might influence the moisture retention during baking. Thus, $100 \%$ purple rice flour gives the lowest digested starch released using the in vitro starch digestibility. The reduction effects on starch digestibility of substituted purple rice flour in wheat biscuits are based on the different starch fractions as well as the other nutrient contents such as fat, fiber, protein, and the phenolic acids [26]. As stated previously, the purple rice flour biscuits which are rich in dietary fiber and amylopectin content [26] had lower amounts of glucose released over time compared to wheat biscuits [27]. The similar result was reported by An et al. [26] that pGI values of black rice flour were significantly lower than those of wheat flour in in vitro starch digestion. In contrast, the biscuits with low moisture content had lower pGI since the gelatinization would be restricted if there is not enough water during heating regardless of the amylose content [27]. Therefore, substituted biscuits with purple rice flour can be estimated as an intermediate GI product (60.64-69.76), which is lower than wheat biscuits $(\mathrm{GI}=72.78)$ [28].

3.2. Physical Properties. The mean values of physical properties of control biscuits and blend flour biscuits are 
TABle 3: Physical and textural characteristics of the biscuits containing different levels of purple rice flours*.

\begin{tabular}{|c|c|c|c|c|c|}
\hline \multirow{2}{*}{ Physical characteristics } & \multirow{2}{*}{ Control wheat biscuit } & \multicolumn{4}{|c|}{ Purple rice flour substitution (\%) } \\
\hline & & 25 & 50 & 75 & 100 \\
\hline Hardness $(N)$ & $71.21 \pm 0.47^{\mathrm{a}}$ & $52.81 \pm 0.69^{\mathrm{b}}$ & $28.52 \pm 0.18^{\mathrm{c}}$ & $22.18 \pm 0.10^{\mathrm{d}}$ & $15.69 \pm 0.14^{\mathrm{e}}$ \\
\hline Width $(W, \mathrm{~mm})$ & $55.17 \pm 0.31^{\mathrm{d}}$ & $57.67 \pm 0.21^{\mathrm{c}}$ & $59.67 \pm 0.21^{\mathrm{b}}$ & $60.50 \pm 0.22^{\mathrm{ab}}$ & $61.17 \pm 0.48^{\mathrm{a}}$ \\
\hline Thickness $(T, \mathrm{~mm})$ & $12.00 \pm 0.26^{\mathrm{a}}$ & $10.50 \pm 0.22^{b}$ & $8.67 \pm 0.21^{c}$ & $8.00 \pm 0.37^{\mathrm{cd}}$ & $7.50 \pm 0.22^{\mathrm{d}}$ \\
\hline Spread ratio $(W / T)$ & $4.61 \pm 0.12^{\mathrm{d}}$ & $5.50 \pm 0.12^{c}$ & $6.91 \pm 0.19^{\mathrm{b}}$ & $7.64 \pm 0.35^{\mathrm{a}}$ & $8.20 \pm 0.30^{\mathrm{a}}$ \\
\hline
\end{tabular}

*Values represent mean \pm standard error. In each row, sample means not having the same letter attached to them are significantly different (Duncan's multiple range test, $p<0.05$ ).

shown in Table 3. The textural characteristic of the biscuits is the important factor contributing to the quality of biscuits. Hardness is one of the key factors, which determine the texture properties of biscuits, and is measured as the peak force needed to penetrate the biscuits. It was significantly decreased $(p<0.05)$ when different levels of purple rice flour were incorporated in the biscuit mix. Purple rice flour biscuits required significantly lower force to snap than the control biscuits. However, the hardness of biscuits was found within the range of the commercial hardness of a biscuit substituted with rice flour [10]. The hardness of blended biscuits is normally lower than the hardness of wheat flour biscuit due to the degradation of macromolecules and low bulk density of flour blends [6]. Moreover, high dietary fiber in the wheat-purple rice blended flour increases the viscosity of biscuits with delaying the accessibility of starch granules to digestive enzymes in the human digestive system.

The addition of purple rice flour in the biscuit formulation changed the width, thickness, and spread ratio due to the protein contents. The thickness of the blend flour biscuits decreased as the protein content decreased in the formula. The 100\% purple rice flour biscuit had the highest spread ratio (greater width and thinner), which is considered to be a positive characteristic of biscuits because the spread ratio is one of the physical parameters that influence the consumer liking scores [6]. A higher spread ratio is thought to improve the acceptability of biscuits. In general, the highest spread ratio was obtained when no gluten was added to the biscuit recipe [6]. Giuberti et al. [9] reported that a higher level of fiber in the biscuit formulation made from modified sticky rice flour absorbed more water; therefore, the biscuit mix has less water left in the mixture which leads to less spread ratio. Chung et al. [10] also reported that biscuits made from different types of rice flour could alter the hardness of the biscuits.

3.3. Color Characteristics. Color is one of the most important factors for the consumer's selection and purchase of baked products [11] including biscuits. The change in color value of the biscuits is presented in terms of $L^{*}, a^{*}$, and $b^{*}$ in Table 4 . The color of biscuits develops further during the later stage of baking with increasing temperature and baking time [6]. The control biscuit showed the highest $L^{*}$ value (74.53) compared to the mean $L^{*}$ value of the substituted biscuits (46.38). The substitutions of purple rice flour in the formulation darkened the surface of the biscuits compared to the control biscuits which had much lower browning index values. The dark color of biscuits generates from the caramelization of the sugar in the recipe or a Maillard reaction during baking at high temperature [6]. Thus, the control biscuits contained the highest protein content (Table 2), the color values revealed a contrast with Ruangchakpet and Sajjaanantakul [19] who reported that more protein incorporation resulted in a darker surface of biscuits. In purple rice flour substitution biscuits, besides the protein level, indications also suggested that purple rice flour is deep purple in color since the naturally high antioxidant contents [2] can contribute to the color changes of the biscuits.

The redness $\left(a^{*}\right)$ also differed among the biscuits since purple rice biscuits are characterized by much darker color with lower protein content when compared to the control biscuits. Redness (positive $a^{*}$ value) of the biscuits shows an increasing trend from the lowest value (3.84) observed in the control biscuits to the highest value (6.08) found in $100 \%$ purple rice flour biscuits. The increase in redness of purple rice flour containing in the biscuits could be attributed to the presence of purple pigments in husk of purple rice. According to Shao et al. [29], phenolic acids and anthocyanins exhibited the antioxidant activities in both DPPH and ABTS assays. The studies on the antioxidants of the biscuits are assured to investigate the radical scavenging ability, which might provide further details in this study. The $b^{*}$ values indicated the yellowness of all biscuits which were significantly different $(p<0.05)$ with increasing level of purple rice flour substitutions. The control biscuit has greater $b^{*}$ value than the substituted biscuits. The yellowness of purple rice flour substitution biscuits decreases due to the degradation of unstable yellow compounds of purple rice flour during baking. Moreover, a decrease in the $b^{*}$ value of the substituted biscuits can also be attributed to the lower $b^{*}$ value (2.16) of $100 \%$ purple rice flour than $100 \%$ wheat flour (13.08) [30]. Hence, the reduction of yellowness of purple rice flour substitution biscuits occurs. The browning index of biscuits is also caused by Maillard reactions and caramelization of sugar during baking process between reducing sugar and amino acids that can increase the antioxidant properties of the baked products [11]. The lightness of biscuits is related not only to the Maillard reactions during baking, but also to the color of the flour used which can affect the browning index of the biscuits. Wheat flour contains more protein than substituted purple rice flour, and the amount of the melanoidins formed in the blend flour biscuits was significantly greater than those in the control biscuits [11]. 
TABLE 4: $L^{*} a^{*} b^{*}$ color values of the biscuits containing different levels of purple rice flours*.

\begin{tabular}{|c|c|c|c|c|c|}
\hline \multirow{2}{*}{ Physical characteristics } & \multirow{2}{*}{ Control wheat biscuit } & \multicolumn{4}{|c|}{ Purple rice flour substitution (\%) } \\
\hline & & 25 & 50 & 75 & 100 \\
\hline \multicolumn{6}{|l|}{ Color values } \\
\hline$L^{*}$ & $74.53 \pm 0.57^{\mathrm{a}}$ & $60.45 \pm 0.10^{\mathrm{b}}$ & $45.33 \pm 0.06^{\mathrm{c}}$ & $40.85 \pm 0.15 \mathrm{~d}$ & $38.88 \pm 0.37^{\mathrm{e}}$ \\
\hline$a^{*}$ & $3.84 \pm 0.08^{\mathrm{d}}$ & $3.98 \pm 0.03^{\mathrm{bc}}$ & $4.07 \pm 0.02^{\mathrm{bc}}$ & $4.39 \pm 0.04 b$ & $6.08 \pm 0.36^{\mathrm{a}}$ \\
\hline$b^{*}$ & $38.65 \pm 0.32^{\mathrm{a}}$ & $12.92 \pm 0.14^{\mathrm{b}}$ & $9.15 \pm 0.24^{c}$ & $5.33 \pm 0.03 d$ & $3.94 \pm 0.10^{\mathrm{e}}$ \\
\hline Browning index & $76.36 \pm 1.02^{\mathrm{a}}$ & $52.18 \pm 0.27^{\mathrm{b}}$ & $28.38 \pm 0.79^{c}$ & $20.97 \pm 0.14 \mathrm{~d}$ & $17.87 \pm 0.31^{\mathrm{e}}$ \\
\hline
\end{tabular}

*Values represent mean \pm standard error. In each row, sample means not having the same letter attached to them are significantly different (Duncan's multiple range test, $p<0.05$ ).

TABLE 5: Bioactive compound contents of the biscuits containing different levels of purple rice flours*.

\begin{tabular}{|c|c|c|c|c|c|}
\hline \multirow{2}{*}{ Bioactive compounds } & \multirow{2}{*}{ Control wheat biscuit } & \multicolumn{4}{|c|}{ Purple rice flour substitution (\%) } \\
\hline & & 25 & 50 & 75 & 100 \\
\hline Total phenolics ( $\mu \mathrm{g}$ GAE/100 g DW) & $6.51 \pm 0.04^{\mathrm{e}}$ & $812.51 \pm 0.60^{\mathrm{d}}$ & $2053.81 \pm 21.60^{c}$ & $2319.92 \pm 2.89^{b}$ & $3012.27 \pm 33.73^{\mathrm{a}}$ \\
\hline Anthocyanins (C3G, mg/kg DW) & $0.28 \pm 0.05^{\mathrm{e}}$ & $9.35 \pm 0.19^{\mathrm{d}}$ & $15.92 \pm 0.49^{\mathrm{c}}$ & $37.44 \pm 1.43^{\mathrm{b}}$ & $51.49 \pm 0.73^{\mathrm{a}}$ \\
\hline Flavonoid contents (mg CE/100 g DW) & $0.15 \pm 0.01^{\mathrm{e}}$ & $0.57 \pm 0.02^{\mathrm{d}}$ & $0.92 \pm 0.01^{\mathrm{c}}$ & $1.13 \pm 0.01^{\mathrm{b}}$ & $1.32 \pm 0.01^{\mathrm{a}}$ \\
\hline DPPH $(\mu \mathrm{mol}$ Trolox/g DW) & $1.07 \pm 0.05^{\mathrm{e}}$ & $15.63 \pm 0.14^{\mathrm{d}}$ & $33.55 \pm 0.12^{\mathrm{c}}$ & $39.61 \pm 0.12^{\mathrm{b}}$ & $49.19 \pm 0.08^{\mathrm{a}}$ \\
\hline ABTS $(\mu \mathrm{mol}$ Trolox/g DW $)$ & $5.49 \pm 0.01^{\mathrm{e}}$ & $14.00 \pm 0.02^{\mathrm{d}}$ & $36.73 \pm 0.01^{\mathrm{c}}$ & $60.45 \pm 0.28^{\mathrm{b}}$ & $96.95 \pm 0.22^{\mathrm{a}}$ \\
\hline
\end{tabular}

*In each row, sample means not having the same letter attached to them are significantly different (Duncan's multiple range test, $p<0.05$ ); values represent mean \pm standard error.

3.4. Antioxidant Compounds and Antioxidant Activities. The overall results of the antioxidant compounds and antioxidant activities of the biscuits obtained from different levels of purple rice flour substitution are shown in Table 5 . The blend flour biscuits significantly increased $(p<0.05)$ all antioxidant compounds (total phenolics, anthocyanins, and flavonoid content) compared to the control biscuits. Total phenolic acids (including free, soluble conjugated, and insoluble bound forms) are found in high level existed in the whole pigmented cereal grains which have gallic acid (GAE) as a major phenolic acid [31]. Jang and $\mathrm{Xu}$ [1] and Loypimai et al. [31] suggested that purple rice is a potential source of phenolic compounds due to the dark-purple pigment of the anthocyanins. The major anthocyanins of purple rice analyzed in this study were cyanidin-3-O-glucoside (C3G), which was reported to have an antidiabetic effect in type 2 diabetes of mice [4]. In case of purple rice flour, it contains high levels of C3G. The $100 \%$ purple rice biscuits had significantly higher $(p<0.05)$ anthocyanin and flavonoid contents, followed by $75 \%, 50 \%$, and $25 \%$ purple rice substitution biscuits, respectively. Thus, purple rice flour was found to suppress the glucose released from starch digestion (Table 2) based on the inhibition of starch digestive enzymes by anthocyanins such as C3G. Shao et al. [29] also reported that black rice from different cultivars had C3G which ranged from 12.03 to $1106.00 \mathrm{mg} / \mathrm{kg}$ DW. The total flavonoid contents of the control biscuit $(0.15 \mathrm{mg}$ catechin equivalence $(\mathrm{CE}) / 100 \mathrm{~g})$ were significantly lower $(p<0.05)$ than those of the substituted biscuits $(1.32 \mathrm{mg} C E / 100 \mathrm{~g})$. Even though the anthocyanin and flavonoid stability of purple rice is affected because of thermal processing, the retention rate of antioxidant compounds is still stable in the biscuits. This study suggested that the substitution of purple rice flour for the wheat flour could be another option to retain bioactive compounds in bakery products such as biscuits, with slightly altered texture characteristics.

The accepted methods used for analyzing antioxidant activities are the ABTS and DPPH radicals based on measuring color degradation [31]. The DPPH assay is normally analyzed aqueous or organic extracts having hydrophilic and lipophilic compounds. On the contrary, the ABTS method commonly evaluates the antioxidant activity of hydrophilic compounds in the extract [31]. Table 5 shows increases in antioxidant activities of the biscuits with increasing substitution in wheat flour. The DPPH radical scavenging activities and radical cation ABTS scavenging activity ranged from 1.07 to $49.19 \mu \mathrm{mol}$ Trolox/g DW and from 5.49 to $96.95 \mu \mathrm{mol}$ Trolox/g DW, respectively. Compared to the control biscuits, the incorporation of purple rice flour showed a significant $(p<0.05)$ increase in the antioxidant activities (DPPH and ABTS assays) of purple rice substitution biscuits (even at the lowest substitution level, 25\% purple rice flour substitution). These results were similar to the report of Shao et al. [29]. Chung et al. [10] reported that increase in antioxidant activities might be attributed to the formation of browning color due to the Maillard reaction during baking process which is in contrast with this study since the results of antioxidant activities are also linked with the concentration of phenolic compounds, anthocyanin, and flavonoids that have antioxidant properties [31]. Many studies also reported a high correlation between DPPH radical scavenging activities and antioxidant contents [29-31].

3.5. Sensory Attributes. The mean liking scores for all attributes of the biscuits for the different levels of purple rice flour substitution in wheat flour are shown in Table 6; these scores were neutral or moderately acceptable (scores 4-6). 
TABLE 6: Mean liking scores of sensory evaluation of the biscuits containing different levels of purple rice flours*.

\begin{tabular}{|c|c|c|c|c|c|}
\hline \multirow{2}{*}{ Attributes } & \multirow{2}{*}{ Control wheat biscuit } & \multicolumn{4}{|c|}{ Purple rice flour substitution (\%) } \\
\hline & & 25 & 50 & 75 & 100 \\
\hline Color & $6.09 \pm 0.07^{\mathrm{a}}$ & $6.00 \pm 0.07^{\mathrm{a}}$ & $5.83 \pm 0.08^{\mathrm{ab}}$ & $5.71 \pm 0.09^{\mathrm{b}}$ & $5.02 \pm 0.13^{\mathrm{c}}$ \\
\hline Overall appearance & $6.26 \pm 0.07^{\mathrm{a}}$ & $5.86 \pm 0.07^{\mathrm{b}}$ & $5.84 \pm 0.08^{\mathrm{b}}$ & $5.78 \pm 0.07^{\mathrm{b}}$ & $5.67 \pm 0.08^{\mathrm{b}}$ \\
\hline Touch/texture & $6.09 \pm 0.07^{\mathrm{a}}$ & $5.68 \pm 0.08^{\mathrm{b}}$ & $5.58 \pm 0.06^{\mathrm{b}}$ & $4.98 \pm 0.11^{\mathrm{c}}$ & $4.28 \pm 0.12^{\mathrm{d}}$ \\
\hline Touch/oiliness & $5.87 \pm 0.07^{\mathrm{a}}$ & $5.83 \pm 0.08^{\mathrm{a}}$ & $5.67 \pm 0.08^{\mathrm{ab}}$ & $5.69 \pm 0.08^{\mathrm{ab}}$ & $5.56 \pm 0.08^{b}$ \\
\hline Sweetness & $6.26 \pm 0.06^{\mathrm{a}}$ & $6.13 \pm 0.06^{\mathrm{a}}$ & $6.26 \pm 0.07^{\mathrm{a}}$ & $6.12 \pm 0.07^{\mathrm{a}}$ & $5.90 \pm 0.08^{\mathrm{b}}$ \\
\hline Crunchiness & $5.73 \pm 0.08^{\mathrm{a}}$ & $5.40 \pm 0.08^{\mathrm{b}}$ & $5.24 \pm 0.07^{\mathrm{b}}$ & $4.62 \pm 0.08^{\mathrm{c}}$ & $4.29 \pm 0.08^{\mathrm{d}}$ \\
\hline Flavor & $6.41 \pm 0.06^{\mathrm{a}}$ & $6.10 \pm 0.09^{\mathrm{b}}$ & $5.74 \pm 0.08^{c}$ & $5.17 \pm 0.08^{\mathrm{d}}$ & $4.71 \pm 0.11^{\mathrm{e}}$ \\
\hline Overall acceptability & $6.14 \pm 0.07^{\mathrm{a}}$ & $5.67 \pm 0.08^{b}$ & $5.54 \pm 0.08^{\mathrm{b}}$ & $4.47 \pm 0.11^{\mathrm{c}}$ & $3.90 \pm 0.12^{\mathrm{d}}$ \\
\hline
\end{tabular}

*In each row, sample means not having the same letter attached to them are significantly different (Duncan's multiple range test, $p<0.05$ ); data are expressed as mean \pm standard error.

The overall acceptability of blended flour biscuits was slightly different $(p<0.05)$ compared to the control biscuits. Color, oiliness, and sweetness of the substituted flour biscuits up to $75 \%$ showed nonsignificant variation $(p>0.05)$ compared to the control biscuits, which consumers liked a lot. The preferred biscuits were enriched with purple rice flour up to $50 \%$ which had significantly different color parameters (Table 4) from the control biscuit. However, overall consumers appear to prefer lighter colored biscuits [11]. In the present study, the term crunchiness was used to describe the consumer preference, which refers to the hardness characteristic of the biscuits. The mean scores of texture and crunchiness of $25 \%$ and $50 \%$ purple rice flour substitutions decreased from the scores of the control biscuits around $8 \%$. The relationship of physical characteristics and sensory evaluation was presented in this study. As the substitution levels increased from $25 \%$ to $100 \%$, the biscuits tended to be much softer. These findings are in agreement with the results indicated in Table 3, wherein the hardness of the biscuits showed a decrease with increase in the purple rice flour incorporation levels. The flavor scores of blended flour biscuits significantly decreased $(p<0.05)$ along with increase in the purple rice flour substitution levels. Few studies have observed the influence of rice flour substitution on the sensory acceptance of biscuits. Mancebo et al. [32] prepared biscuits from different ratios of white rice flour mixed with protein and showed good overall acceptability scores. The purple rice flour had a dark color, due to its high antioxidant content, which might cause the reduction of sensory liking scores shown for color, overall appearance, and texture of the substituted biscuits [6]. The mean score of overall acceptability decreased gradually from 5.54 to 3.90 as the purple rice flour incorporation levels were increased beyond $50 \%$ in the biscuit mixes. This indicates that at substitution levels of more than $50 \%$, the preference on the biscuits in terms of overall acceptability was significantly reduced. In the case of all sensory attributes of $25 \%$ and $50 \%$ purple rice substitution biscuits, they scored similar values to the control biscuits with higher antioxidants and gave the best overall responses to the physical changes. However, the liking score values for the $75 \%$ and $100 \%$ purple rice biscuits showed significantly decreasing values for all attributes when compared to the control wheat biscuits, but the biscuits contained higher levels of antioxidants.

\section{Conclusions}

This study revealed that the purple rice flour could be an acceptable partial wheat substitute to produce biscuits with a low starch digestibility, low pGI with high protein digestibility, and natural antioxidant contents. Inclusion of increasing purple rice flour led to a $54 \%$ increase in the digestible protein while at the same time reducing the rate of starch digestion by $58 \%$. Considering that biscuits made with wheat flour have low dietary fiber and protein contents, it seems that maximizing protein digestibility and starch digestibility from the purple rice flour substitution is desirable to increase the nutritional properties of the biscuits. Further research would be needed to improve the formulation regarding the fat content in order to produce a lower fatcontaining biscuit. Although the physical characteristics of the biscuits were significantly changed, only small negative effects were observed during sensory evaluation up to $50 \%$ of purple rice flour substitution compared to the control biscuits. Thus, the present finding suggests that value-added biscuits could be produced by supplementing purple rice flour up to $50 \%$. This could be recommended as suitable food for people with diabetes who need to consume a lower digestibility starch-containing food, which assumed that a lower fat content would be achieved.

\section{Data Availability}

The authors confirm that the data supporting the findings of this study are available within the article.

\section{Conflicts of Interest}

The authors declare that they have no conflicts of interest regarding the publication of this paper.

\section{Acknowledgments}

Warinporn Klunklin would like to acknowledge Chiang Mai University, Thailand, and the Post Graduate Research Fund, Lincoln University, Canterbury, NZ, for funding this project and the sensory panelists who were involved in this research work. 


\section{References}

[1] S. Jang and Z. Xu, "Lipophilic and hydrophilic antioxidants and their antioxidant activities in purple rice bran," Journal of Agricultural and Food Chemistry, vol. 57, no. 3, pp. 858-862, 2009.

[2] R. Yawadio, S. Tanimori, and N. Morita, "Identification of phenolic compounds isolated from pigmented rices and their aldose reductase inhibitory activities," Food Chemistry, vol. 101, no. 4, pp. 1616-1625, 2007.

[3] A. Pasqualone, A. M. Bianco, V. M. Paradiso et al., "Production and characterization of functional biscuits obtained from purple wheat," Food Chemistry, vol. 180, pp. 64-70, 2015.

[4] F. S. Hosseinian, W. Li, and T. Beta, "Measurement of anthocyanins and other phytochemicals in purple wheat," Food Chemistry, vol. 109, no. 4, pp. 916-924, 2008.

[5] J. Park, I. Choi, and Y. Kim, "Cookies formulated from fresh okara using starch, soy flour and hydroxypropyl methylcellulose have high quality and nutritional value," LWT-Food Science and Technology, vol. 63, no. 1, pp. 660-666, 2015.

[6] S. Sharma, D. C. Saxena, and C. S. Riar, "Nutritional, sensory and in-vitro antioxidant characteristics of gluten free cookies prepared from flour blends of minor millets," Journal of Cereal Science, vol. 72, pp. 153-161, 2016.

[7] M. Giarnetti, V. M. Paradiso, F. Caponio, C. Summo, and A. Pasqualone, "Fat replacement in shortbread cookies using an emulsion filled gel based on inulin and extra virgin olive oil," LWT-Food Science and Technology, vol. 63, no. 1, pp. 339-345, 2015.

[8] A. Torbica, M. Hadnađev, and C. T. Hadnađev, "Rice and buckwheat flour characterisation and its relation to cookie quality," Food Research International, vol. 48, no. 1, pp. 277-283, 2012.

[9] G. Giuberti, A. Marti, P. Fortunati, and A. Gallo, "Gluten free rice cookies with resistant starch ingredients from modified waxy rice starches: nutritional aspects and textural characteristics," Journal of Cereal Science, vol. 76, pp. 157-164, 2017.

[10] H. J. Chung, A. Cho, and S. T. Lim, "Utilization of germinated and heat-moisture treated brown rices in sugar-snap cookies," LWT-Food Science and Technology, vol. 57, no. 1, pp. 260-266, 2014.

[11] S. Chandra, S. Singh, and D. Kumari, "Evaluation of functional properties of composite flours and sensorial attributes of composite flour biscuits," Journal of Food Science and Technology, vol. 52, no. 6, pp. 3681-3688, 2015.

[12] AOAC (Association of Official Agricultural Chemistry), Official Methods of Analysis International, AOAC International, Gaithersburg, MD, USA, 17th edition, 2000.

[13] M. O. Reed, Y. Ai, J. L. Leutcher, and J. Jane, "Effects of cooking methods and starch structures on starch hydrolysis rates of rice," Journal of Food Science, vol. 78, no. 7, pp. 1076-1081, 2013.

[14] W. R. Akeson and M. A. Stahmann, "A pepsin pancreatin digest index of protein quality evaluation," Journal of $\mathrm{Nu}$ trition, vol. 83, no. 3, pp. 257-261, 1964.

[15] J. A. Monro, S. Mishra, and B. Venn, "Baselines representing blood glucose clearance improve in vitro prediction of the glycemic impact of customarily consumed food qualities," British Journal of Nutrition, vol. 103, no. 2, pp. 295-305, 2010.

[16] I. Goni, A. Garcia-Alonso, and F. Saura-Calixto, "A starch hydrolysis procedure to estimate glycemic index," Nutrition Research, vol. 17, no. 3, pp. 427-437, 1997.

[17] AACC (American Association of Cereal Chemists), Baking Quality of Cookie Flour-Micro Method, Approved Method 10-50D, American Association of Cereal Chemists, St. Paul, MN, USA, 2000.
[18] N. Sozer, L. Cicerelli, R. L. Heiniö, and K. Poutanen, "Effect of wheat bran addition on in vitro starch digestibility, physicomechanical and sensory properties of biscuits," Journal of Cereal Science, vol. 60, no. 1, pp. 105-113, 2014.

[19] A. Ruangchakpet and T. Sajjaanantakul, "Effect of browning on total phenolic, flavonoid content and antioxidant activity in Indian Gooseberry (Phyllanthus emblica Linn.)," Kasetsart Journal, vol. 41, pp. 331-337, 2007.

[20] I. Kaneda, F. Kubo, and H. Sakurai, "Antioxidative compounds in the extracts of black rice bran," Journal of Health Science, vol. 52, no. 5, pp. 495-511, 2006.

[21] R. Re, N. Pellegrini, A. Proteggente, A. Pannala, M. Yang, and C. Rice-Evans, "Antioxidant activity applying an improved ABTS radical cation decolourization assay," Free Radical Biology and Medicine, vol. 26, no. 9-10, pp. 1231-1237, 1999.

[22] P. Mahakunakorn, M. Tohda, Y. Murakami, K. Matsumoto, and H. Watanabe, "Antioxidant and free radical-scavenging activity of chitosan and its related constituents," Biological and Pharmaceutical Bulletin, vol. 27, no. 1, pp. 38-46, 2004.

[23] J. C. Okaka and N. N. Potter, "Functional and storage properties of cowpea-wheat flour blends in bread making," Journal of Food Science, vol. 42, no. 3, pp. 828-833, 1977.

[24] U. Uthumporn, W. L. Woo, A. Y. Tajul, and A. Fazilah, "Physico-chemical and nutritional evaluation of cookies with different levels of eggplant flour substitution," CyTA-Journal of Food, vol. 13, no. 2, pp. 220-226, 2015.

[25] B. Zhang, G. Liu, D. Ying, L. Sanguansri, and M. A. Augustin, "Effect of extrusion conditions on the physico-chemical properties and in vitro protein digestibility of canola meal," Food Research International, vol. 100, pp. 658-664, 2017.

[26] J. S. An, I. Y. Bae, S. Han, S. J. Lee, and H. G. Lee, "In vitro potential of phenolic phytochemicals from black rice on starch digestibility and rheological behaviors," Journal of Cereal Science, vol. 70, pp. 214-220, 2016.

[27] M. Frei, P. Siddhuraju, and K. Becker, "Studies on the in vitro starch digestibility and the glycemic index of six different indigenous rice cultivars from the Philippines," Food Chemistry, vol. 83 , no. 3, pp. 395-402, 2003.

[28] J. C. Miller, "Important of glycemic index in diabetes," The American Journal of Clinical Nutrition, vol. 59, no. 3, pp. 74757525, 1994.

[29] Y. Shao, Z. Hu, Y. Yu, R. Mou, Z. Zhu, and T. Beta, "Phenolic acids, anthocyanins, proanthocyanidins, antioxidant activity, minerals and their correlations in non-pigmented, red, and black rice," Food Chemistry, vol. 239, pp. 733-741, 2018.

[30] W. Klunklin and G. Savage, "Physicochemical, antioxidant properties and in vitro digestibility of wheat-purple rice flour mixtures," International Journal of Food Science and Technology, 2018, In press.

[31] P. Loypimai, A. Moongngarm, and P. Chottanom, "Phytochemicals and antioxidant capacity of natural food colorant prepared from black waxy rice bran," Food Bioscience, vol. 15, pp. 4-41, 2016.

[32] C. M. Mancebo, P. Rodriguez, and M. Gomez, "Assessing rice flour-starch-protein mixtures to produce gluten free sugarsnap cookies," LWT-Food Science and Technology, vol. 67, pp. 127-132, 2016. 


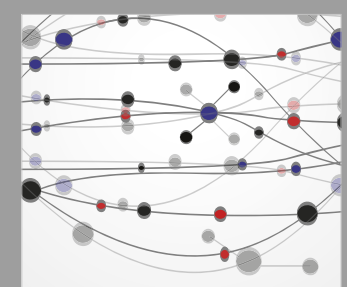

The Scientific World Journal
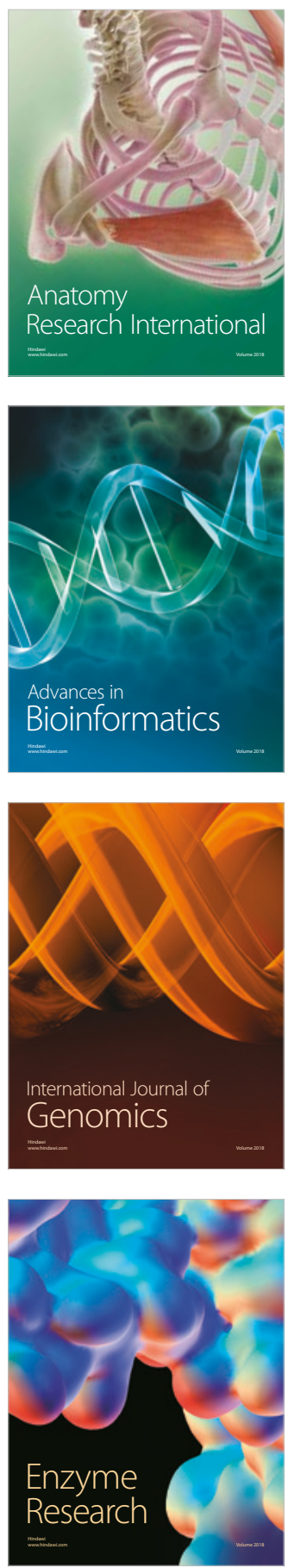
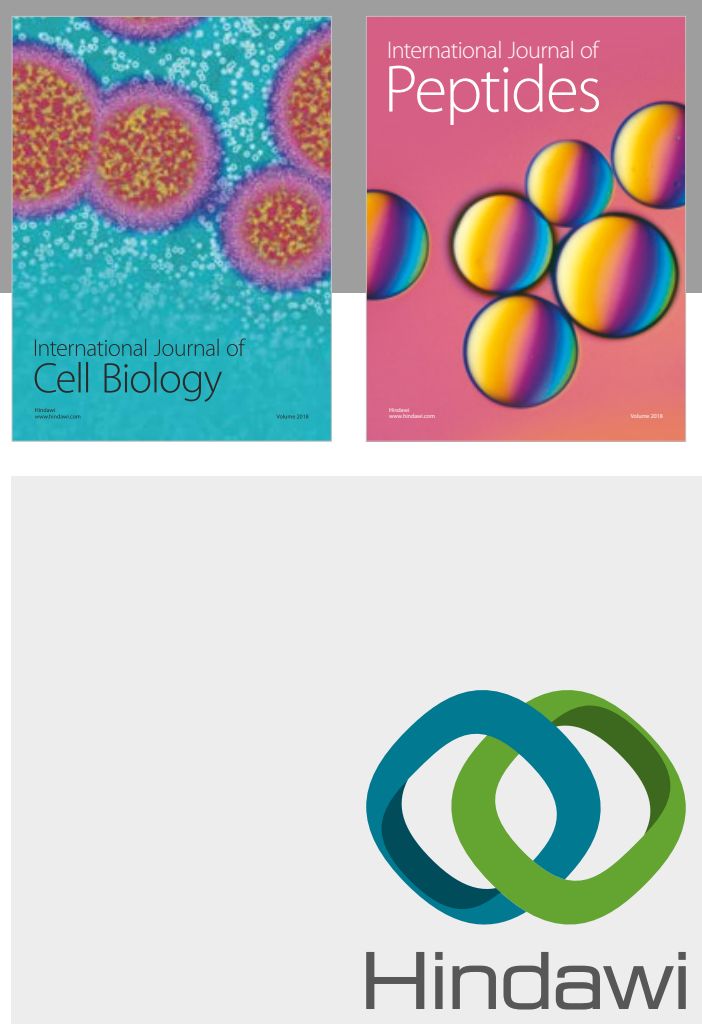

Submit your manuscripts at

www.hindawi.com
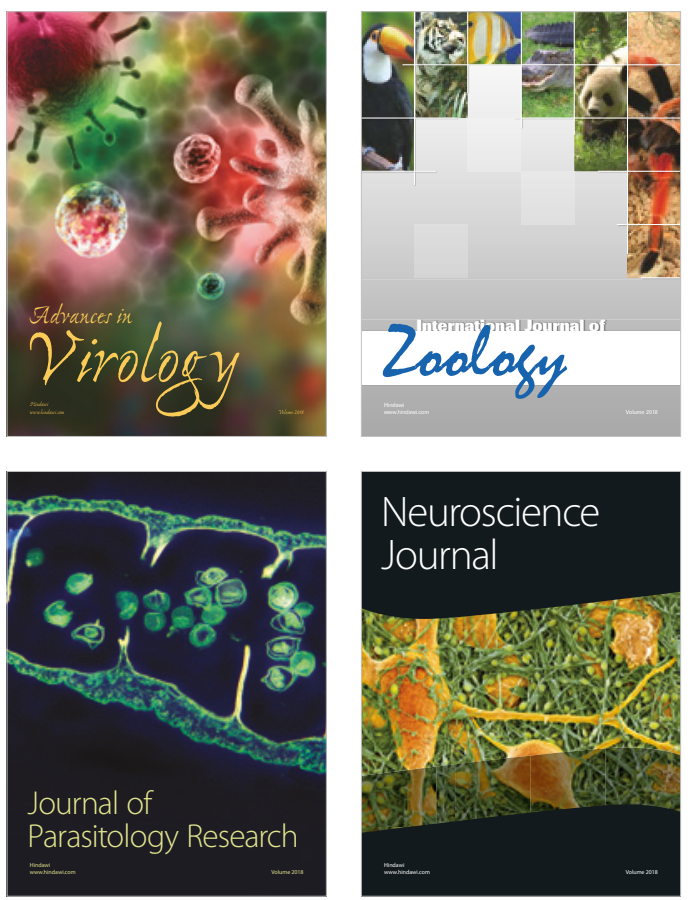
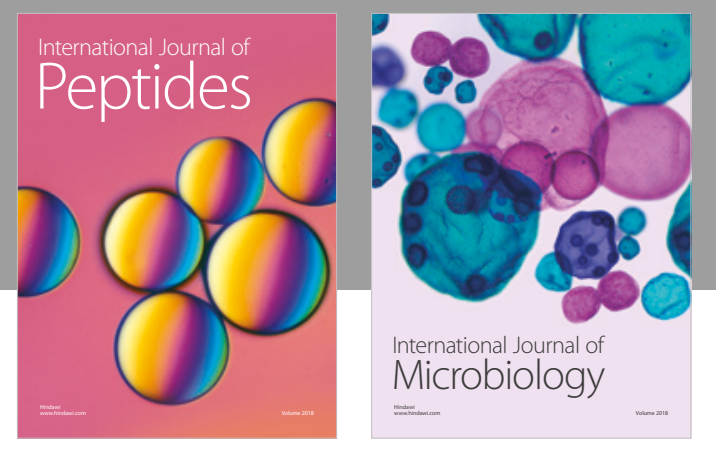

nternational Journal of Microbiology
Journal of
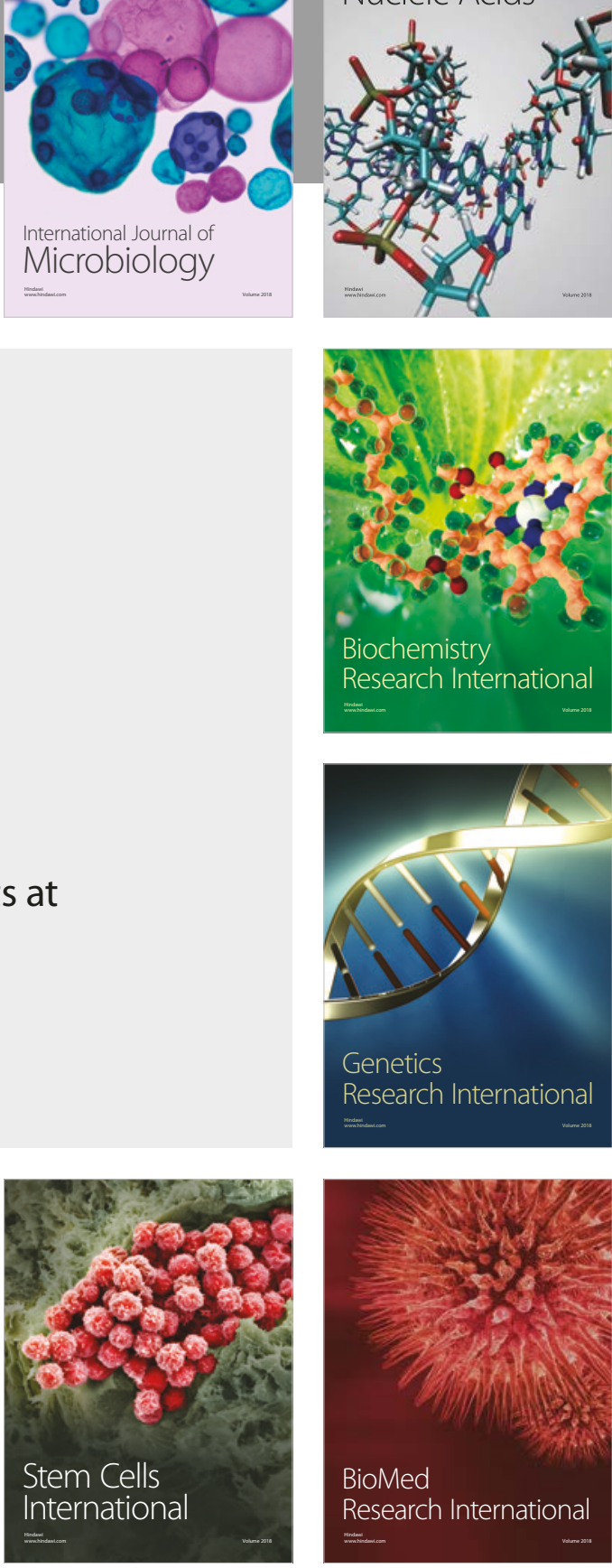
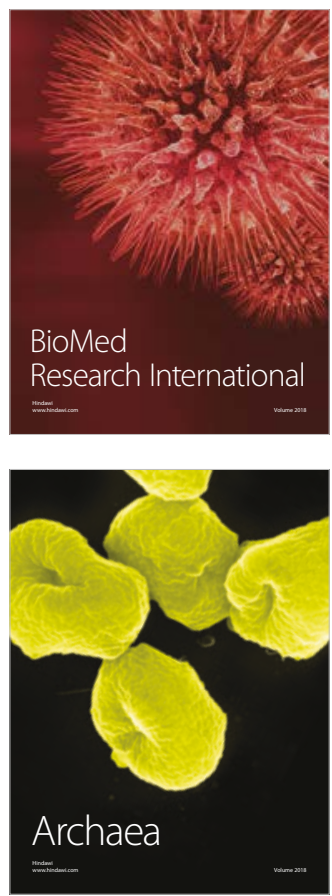